\title{
Peptide Mimic Isolated by Autoantibody Reveals Human Arrest Defective 1 Overexpression Is Associated with Poor Prognosis for Colon Cancer Patients
}

Beihai Jiang, ${ }^{*}$ Tingting Ren, ${ }^{*}$ Bin Dong, ${ }^{\dagger}$ Like Qu, ${ }^{*}$ Genglin Jin, ${ }^{*}$ Jianning $\mathrm{Li},{ }^{*}$ Hong Qu, ${ }^{\ddagger}$ Lin Meng, ${ }^{*}$ Caiyun Liu, ${ }^{*}$ Jian Wu, ${ }^{*}$ and Chengchao Shou*

From the Key Laboratory of Carcinogenesis and Translational Research (Ministry of Education), " Department of Biochemistry and Molecular Biology, Peking University School of Oncology, and the Core Facility of Peking University School of Oncology, ${ }^{\dagger}$ Beijing Cancer Hospital and Institute; and the College of Life Sciences, ${ }^{\ddagger}$ Peking University, Beijing, China

Tumor-associated antigens, which induce the generation of autoantibodies, are useful as cancer biomarkers in early detection and prognostic prediction of cancer. To isolate a novel cancer marker, we used serum antibodies from colon cancer patients to screen a phage display peptide library. A positive peptide 249C (VPLYSNTLRYGF) that could specifically react with serum from colon cancer patients was isolated, and the corresponding antigen-human arrest defective 1 (ARD1A), which shares an identical LYSNTL motif with 249C, was identified. Both immunological assays and three-dimensional structure analysis showed that the LYSNTL region is an epitope of ARD1A. Using ELISA and immunohistochemistry, we found anti-ARD1A antibody levels in serum from patients with colon cancer were significantly higher than those in healthy volunteers $(P<0.001)$, and ARD1A expression was detected in $84.1 \%(227 / 270)$ of colon cancer tissues compared with $22.7 \%(55 / 242)$ of matched noncancerous tissues $(P<$ $0.001)$ and $4.8 \%(2 / 42)$ of benign lesions $(P<0.001)$. Furthermore, multivariate analysis with Cox proportional hazards regression models revealed that ARD1Apositive patients had significantly shortened overall survival (OS) $(\mathrm{HR}, 1.91, P=0.039)$ and borderline significantly shortened disease-free survival (DFS) (HR, 1.70; $P=0.068$ ). Kaplan-Meier survival curves also showed that ARD1A expression was associated significantly with shortened DFS $(P=0.037)$ and OS $(P=$ 0.019). These results indicate that ARD1A is a novel tumor-associated antigen and a potential prognostic fac- tor for colon cancer. (Am J Pathol 2010, 177:1095-1103; DOI: 10.2353/ajpath.2010.091178)

Colon cancer is one of the most common cancers worldwide and is the second leading cause of cancer death in developed countries. ${ }^{1}$ The 5 -year survival rate of patients with colon cancer has improved during the past decade because of advances in screening and systemic treatment, but the survival rate remains relatively poor in patients with stage III and IV cancer. ${ }^{2}$ Colon cancer is treated mainly by surgery, and it would be beneficial if the prognosis after initial surgery could be predicted. Although the tumor-nodemetastasis (TNM) system is helpful for this purpose, ${ }^{2}$ it is not always correlated with outcome of the cancer patients. To predict the prognosis more exactly, new molecular markers are needed to be exploited.

Considerable evidence has shown that an immune response in the form of autoantibodies to various tumor antigens was developed in patients with cancer. ${ }^{3-7}$ Thus, autoantibodies in the serum of patients with colon cancer could be used to isolate specific tumor-associated antigens. More sensitive and specific molecular markers have the potential to improve the preclinical diagnosis of primary and recurrent colon cancer, as well as hold the

Supported by National Natural Sciences Foundation of China (30600287) National 973 Program (2009CB521805), and National 863 Program (2006AA02A249, 2006AA02A402, and 2007AA021103).

B.J. and T.R. contributed equally to this study.

Accepted for publication May 20, 2010.

Supplemental material for this article can be found on http://ajp. amjpathol.org.

Current address of T.R.: Musculoskeleted Tumor Center, Peking University People's Hospital, Beijing, China; of J.L.: Department of Biochemistry, Basic College of Ningxia Medical University, Yinchuan, China.

Address reprint requests to Chengchao Shou, M.D., Ph.D., Key Laboratory of Carcinogenesis and Translational Research (Ministry of Education), Department of Biochemistry and Molecular Biology, Peking University School of Oncology, Beijing Cancer Hospital and Institute, 52 Fucheng Road, Haidian District, Beijing 100142, China. E-mail: scc@bjcancer.org. 
promise of prognostic value. Phage display libraries have proved to be a useful tool for identifying autoantigens or epitopes recognized by antibodies. ${ }^{8-12}$ Selection of peptide libraries with mAbs and mixed serum from patients with disease has led to the isolation of immunoreactive peptide epitopes. ${ }^{4,12-14}$ The strategy has also led to the identification of some tumor-associated antigens from phage display libraries using patient serum. ${ }^{4,12}$

In the present study, by screening a phage display peptide library with serum antibodies from patients with colon cancer, together with bioinformatic analysis and a series of immune experiments, we first revealed that human arrest defective 1 (ARD1A) may serve as an indicator of unfavorable prognosis in colon cancer.

\section{Materials and Methods}

\section{Cell Line and Cell Culture Conditions}

The LoVo colon adenocarcinoma cells were purchased from American Type Culture Collection (ATCC, Manassas, VA). The LoVo cells were grown in DMEM (Gibco) supplement with $10 \%$ fetal bovine serum (FBS, PAA Laboratories, Pasching, Austria) and antibiotics (100 units $/ \mathrm{ml}$ penicillin and $100 \mu \mathrm{g} / \mathrm{ml}$ streptomycin) at $37^{\circ} \mathrm{C}$ in a humidified incubator with $5 \% \mathrm{CO}_{2}$.

\section{Peptide Screening and Phage ELISA}

Sera from five patients with colon cancer before any therapeutic intervention were obtained from Tissue Bank of Peking University School of Oncology. The clinicopathological features and TNM staging are summarized in Supplemental Table S1 at http://ajp.amjpathol.org. Control serum samples were obtained from five healthy ageand sex-matched blood-donor volunteers. Informed consent was obtained from each person, and the study was approved by the Hospital Research Ethics Committee. The biopanning process consisted of four rounds to select the phages binding to IgGs in serum from the five patients with colon cancer. To enhance the selection of peptides binding to specifically IgGs associated with colon cancer, during each round, $1.5 \times 10^{11}$ plaqueforming units (pfu) of the Ph.D.-12 phage display peptide library (New England Biolabs, Beverly, MA) were preincubated with IgGs purified from $50 \mu$ l of normal serum pooled from five healthy volunteers and immobilized on Protein G Sepharose 4 Fast Flow (GE Health care, Uppsala, Sweden) to remove nonspecific binding clones. After the preclearing step, the phage library was selected onto the pool of IgGs purified from patient serum. Phage clones bound to the patient-derived IgGs on beads were amplified by direct infection with host Escherichia coli strain ER2738 grown to the log phase. Amplified phages were used in the next cycle.

After four rounds of selection, 1000 plaques were picked up randomly and analyzed for reactivity with serum from colon cancer patients using phage ELISA. Amplified phages from a single clone were added to the wells of a microtiter plate precoated with a 1:200 dilution of serum from colon cancer patients or healthy volunteers in $0.1 \mathrm{M}$ of bicarbonate buffer $(\mathrm{pH} 9.5)$ and then blocked with $5 \%$ skim milk in PBS. The plate was incubated at room temperature for 1 hour and washed five times with $0.05 \%$ Tween-20/PBS. Bound phages were detected by incubation with HRP-conjugated anti-M13 antibody (Amersham Biosciences, Piscataway, NJ) for 1 hour, followed by washing and addition of a peroxidase substrate (o-phenylenediamine, $0.4 \mathrm{mg} / \mathrm{ml}$ ) in citrate-phosphate buffer ( $\mathrm{pH}$ 5.0) containing $0.02 \%(\mathrm{v} / \mathrm{v}) \mathrm{H}_{2} \mathrm{O}_{2}$. The reaction was stopped with $50 \mu \mathrm{l}$ of $12.5 \% \mathrm{H}_{2} \mathrm{SO}_{4}$. Absorbance at $490 \mathrm{~nm}$ was determined using a microplate reader (Bio-Rad model 550, Bio-Rad, Hercules, CA). Single-stranded phage DNA was prepared from $10 \mathrm{immu}$ nopositive clones using standard techniques as described in the phage display peptide library kit and sequenced by Sangon Company (Shanghai, China).

\section{Expression of Recombinant GST Peptide Fusion Proteins and His-ARD1A in E. coli}

To make the glutathione S-transferase -249C (GST-249C) fusion protein, the sense (5'-GATCCGTTCCTCTGTATAGTAATACGCTTCGTTATGGGTTTTGATATCC-3') and the antisense (5'-TCGAGGATATCAAAACCCATAACGAAGCGTATTACTATACAGAGGAACG-3') oligonucleotide fragments encoding the positive clone 249C, with stop codon, EcoRV site, and sticky ends of BamHI/Xhol shown in italics, were annealed and inserted into the pGEX-4T-1 vector (Amersham Biosciences). To prepare His-ARD1A protein, ARD1A cDNA fragment containing the full-length coding region was amplified using the polymerase chain reaction (PCR) method with plasmid pGEX-5X-3ARD $1 A^{15}$ as a template and two primers (5'-ATTGGATCCATGAACATCCGCAATGCGAG-3' and 5'- AATGTCGACTAGGAGGCTGAGTCGGAG-3'). The PCR products were purified and inserted into a prokaryotic expression system pET-28a (+) (Novagen, Gibbstown, NJ). DNA of recombinants was verified by digestion with restriction endonucleases and then confirmed by DNA sequence analysis.

For the preparation of GST-249C and His-ARD1A proteins, transformed bacteria were cultured in $200 \mathrm{ml}$ of LB medium with ampicillin and kanamycin, respectively, to an optical density of 0.8 at $600 \mathrm{~nm}$. Next, $0.5 \mathrm{mmol} / \mathrm{L}$ isopropyl-1-thio- $\beta$-D-galactopyranoside (IPTG) was added, and the cultures were further incubated for 5 hours at $30^{\circ} \mathrm{C}$. Cells were collected by centrifugation and resuspended in $20 \mathrm{ml}$ PBS with $1 \mathrm{mmol} / \mathrm{L}$ phenylmethanesulfonyl fluoride and $1 \mathrm{mg} / \mathrm{ml}$ lysozyme. Cell suspensions were sonicated, followed by centrifugation at 12,000 rpm for 10 minutes at $4^{\circ} \mathrm{C}$. The GST-249C fusion protein was purified with glutathione beads according to the manufacturer's instructions (Amersham Biosciences), and the His-ARD1A protein was purified with Ni-NTA Agarose (Qiagen, Valencia, CA).

\section{Immunization and Binding Assays}

To detect whether peptide 249C is an epitope of ARD1A, GST-249C and His-ARD1A proteins were prepared. Six- 
to eight-week-old female BALB/c mice (obtained from the Animal Center of the Chinese Medical Academy) were immunized subcutaneously with $40 \mu \mathrm{g}$ of GST-249C or GST emulsified in complete Freund's adjuvant (Sigma, St. Louis, MO). Mice received three boosters of the antigen every three weeks. Serum was collected on days 0 (preimmune) and 7 after the fourth immunization.

The reactivity of antipeptide $249 \mathrm{C}$ serum with ARD1A was tested by Western blotting or immunoprecipitation (IP) analysis using His-ARD1A or lysates from LoVo cells expressing endogenous ARD1A. ${ }^{15}$ For Western blotting, $100 \mathrm{ng}$ of His-ARD1A protein or $100 \mu \mathrm{g}$ cell lysates (prepared in lysis buffer containing $50 \mathrm{mmol} / \mathrm{L}$ Tris- $\mathrm{Cl}[\mathrm{pH}$ 7.4], $50 \mathrm{mmol} / \mathrm{L} \mathrm{NaCl}, 1 \%$ Triton X-100, 1 mmol/L EDTA, $1 \mathrm{mmol} / \mathrm{L}$ phenylmethanesulfonyl fluoride, $1 \mu \mathrm{g} / \mathrm{ml}$ aprotinin, and $1 \mu \mathrm{g} / \mathrm{ml}$ leupeptin) were subjected to $12 \%$ SDS-PAGE and transferred to nitrocellulose membranes. The membranes were blocked with 5\% skim milk in PBS and probed with either a 1:50 dilution of serum from mice immunized with GST-249C or with monoclonal antibody (14D4) against ARD1 $A^{15}$ for 1 hour at room temperature. Preimmunized mouse serum (1:50 dilution), and serum from mice immunized with GST (1:50 dilution) were used as negative controls. After washing with PBST, the antigen-antibody complex on the membrane was detected by incubating with HRP-conjugated secondary antibody and then developed with an enhanced chemiluminescence system (Amersham Biosciences).

For IP, $200 \mu \mathrm{g}$ lysates from LoVo cells were incubated with anti-ARD1A mAb, $10 \mathrm{C} 12,{ }^{15}$ or $10 \mu \mathrm{l}$ of serum from mice immunized with GST-249C for 2 hours at $4^{\circ} \mathrm{C}$ followed by the mixing with protein $\mathrm{G}$ beads. Preimmunized mouse serum and serum from mice immunized with GST were used as negative controls. Immunocomplexes were eluted in the sample buffer, boiled, and subjected to Western blotting.

\section{Three-Dimensional Structure Prediction}

The sequences of the peptides were compared with protein sequence databases by basic local alignment search tool (BLAST) homology search. To analyze the location of the sequence shared by $249 \mathrm{C}$ and ARD1A, the amino acid residue sequence of ARD1A was compared with the primary sequences in the Protein Data Bank through WUBlast2 in http://www.ebi.ac.uk. The best match, 2OBO, a complex of human Mak3 homolog with acetyl-coenzyme A, was used as a structural model. The three-dimensional structure of ARD1A was modeled and refined by the Homology program and Discover program in Insight II (2000) software package (Accelrys Inc., San Diego, CA).

\section{Serum Samples and Tissue Specimens}

All specimens were obtained from Tissue Bank of Peking University School of Oncology. The samples from patients who had undergone preoperative chemotherapy or radiotherapy were excluded from the present study. Informed consent was obtained from each patient, and the study was approved by the Hospital Research Ethics Committee.
Serum samples from 198 patients (range, 19-80 years) with colon cancer before surgery and 200 healthy blood donors (range, 24-76 years) were collected between 2003 and 2008. Clinicopathological features and TNM staging of the patients were summarized in Supplemental Table S2 at $h$ ttp://ajp.amjpathol.org. Complete follow-up data were available for 149 patients for a median of 34 months (range, 1-60 months).

Specimens from 270 patients with colon cancer were collected during primary tumor surgical resection over the period 1996-2002. The median age at diagnosis was 63 years (range, 23-85 years). Formalin-fixed paraffinembedded specimens from these patients and from 242 matched adjacent noncancerous tissues were collected for immunohistochemical analysis. Primary histological examination was performed by two senior pathologists to confirm the diagnosis of colon cancer, establish the pathological stage, and select areas that contained at least $75 \%$ tumor cells. The clinicopathological characteristics of patients are detailed in Supplemental Table S3 at http://ajp.amjpathol.org. Follow-up data were available for all patients, with a median follow-up of 48 months. In addition, 27 colitis and 15 colonic adenoma specimens were examined.

Another 40 cancer tissue specimens, as well as the matched noncancerous colon tissue both adjacent to (at a distance of $2 \mathrm{~cm}$ ) and distant from (at a distance of 5 $\mathrm{cm}$ or surgical margin) were obtained from patients immediately after surgery during the period 2007-2008 and stored at $-80^{\circ} \mathrm{C}$ until processed for Western blotting. Serum from each patient was also collected for detecting the antibody against ARD1A. The clinical features of the 40 patients in the study are shown in Supplemental Table S4 at http://ajp.amjpathol.org.

\section{Serum ELISA}

The reactivity of human serum antibody to ARD1A protein was tested by ELISA. The microplates were coated with 5 $\mu \mathrm{g} / \mathrm{ml}$ of His-ARD1A in $0.1 \mathrm{M}$ of bicarbonate buffer $(\mathrm{pH}$ 9.5) then blocked with 5\% skim milk in PBS. A 1:200 dilution of patient serum was added to each well. Bound antibodies were detected using HRP-conjugated antihuman IgG antibody (Zhong Shan Co., Beijing, China) with a peroxidase substrate, as described earlier. The cutoff used was the mean absorbance of the healthy volunteers plus 2 SDs.

\section{Western Blot Analysis}

To detect ARD1A expression in cancerous, adjacent noncancerous, and distant noncancerous colon tissues from the same patient, specimens of approximately the same size $\left(\sim 100 \mathrm{~mm}^{3}\right)$ were washed several times with PBS then crushed in $200 \mu \mathrm{l}$ of lysis buffer. Protein concentrations were measured using the Protein BCA Assay (Pierce Rockford, IL). Forty micrograms of total protein were subjected to Western blotting. Nitrocellulose membranes were incubated with ARD1A antibody 14D4. Band 
intensity was quantified using National Institutes of Health Scion Image software and normalized to GAPDH.

\section{Immunohistochemical Analysis}

The specificity of the mouse mAb 14D4 against ARD1A was characterized in our previous study. ${ }^{15}$ For immunohistochemical staining, all specimens were fixed in freshly prepared $10 \%$ neutral buffered formalin, embedded in paraffin, and cut into 5- $\mu \mathrm{m}$ sections. After baking at $60^{\circ} \mathrm{C}$ overnight, sections were dewaxed and rehydrated. Endogenous peroxidase activity was blocked by $3 \%$ hydrogen peroxide for 10 minutes at room temperature. After blocking with $5 \%$ skim milk, sections were incubated with the 14D4 antibody at $4^{\circ} \mathrm{C}$ overnight followed by incubation with second antibody from the EnVisionTM kit (Dako Cytomation, Carpinteria, CA) for 30 minutes at room temperature. The reaction product was visualized with diaminobenzidine (Sigma) for 5 minutes at room temperature. Sections were counterstained with hematoxylin. Purified IgG from normal mouse serum was used as a negative control. ARD1A immunoreactivity was evaluated independently by two experienced pathologists without any knowledge of the clinical data. Tissue samples were estimated in a consecutive analysis to ensure maximal internal consistency. We assessed both the percentage of positive cells and the intensity of cytoplasmic staining in 10 randomly chosen microscopic fields. Assays were scored as negative if $<10 \%$ of tumor cells were stained and positive if $\geq 10 \%$ of tumor cells were stained. Staining intensity was classified as follows: 0 , no staining or staining in $<10 \%$ of tumor cells; $1+$, weak to moderate staining in 10 to $20 \%$ of tumor cells; $2+$, strong staining in 10 to $20 \%$ of tumor cells or weak staining in 20 to $50 \%$ of tumor cells; $3+$, moderate to strong staining in 20 to $50 \%$ of tumor cells or staining in $>50 \%$ of tumor cells. ${ }^{16}$

\section{Statistical Analysis}

The Fisher's exact test was performed to evaluate the possible differences in serum anti-ARD1A antibody levels between patients with colon cancer and healthy volunteers. In immunohistochemical analysis, colon cancer specimens were categorized as either ARD1A-positive or ARD1A-negative. The association between ARD1A expression and clinicopathological variables was analyzed using the Fisher's exact test. The impact of ARD1A expression on DFS and OS was assessed with the hazard ratio (HR; relative risk of relapse or death in the ARD1Apositive group) calculated by Cox multivariate proportional hazards regression model. The multivariate model was adjusted for ARD1A expression in tumors, age, sex, clinical stage, histological type. Survival curves were estimated using the Kaplan-Meier method and compared with the log-rank test. Statistical analyses were performed using SPSS software 13.0 (SPSS, Inc., Chicago, IL). All P values are two-sided, and $P<0.05$ was considered statistically significant.
Table 1. Peptide Sequences Displayed by Phage Binding to Purified IgGs of Patients with Colon Cancer

\begin{tabular}{cl}
\hline Peptides & Sequence \\
\hline $249 \mathrm{C}$ & VPLYSNTLRYGF* \\
$164 \mathrm{~B}$ & SYLTTLRYGNMS \\
$238 \mathrm{~B}$ & TQQSVFSTTLMY \\
$93 \mathrm{~A}$ & IPLPPPSRPFFK \\
$211 \mathrm{~B}$ & QPVDMPYFRTHP \\
\hline
\end{tabular}

*249C and 164B had a 'TLRYG' motif shown in bold type.

\section{Results}

\section{Peptides Specially Reacted with Serum from Colon Cancer Patients Were Identified}

We used a random 12-mer phage display peptide library composed of $1.5 \times 10^{11}$ independent phage clones to select peptides specifically binding to IgGs associated with colon cancer. The total number of phages bound to serum from patients with colon cancer increased from $1.8 \times 10^{6} \mathrm{pfu}$ in the first round to $4.0 \times 10^{7} \mathrm{pfu}$ in the fourth round. After four rounds of selection, roughly $1 \%$ (10/1000) of phage clones exhibited binding activity to serum from patients with colon cancer (data not shown). DNA from 10 positive clones that specifically reacted with serum from patients was sequenced, and their amino acid sequences were shown in Table 1. Among 10 phage clones examined, five types of peptides were obtained. 164B and 249C had a TLRYG motif, whereas no obvious consensus motif was found in other clones.

\section{Peptide 249C Sharing Identical Motif with $A R D 1 A$ and Inducing Antibody Recognizing ARD1A}

The peptide 249C showed significant homology to the residues 121-126 (LYSNTL) of ARD1A by BLAST homology search (Figure $1 \mathrm{~A}$ ). The epitope recognized by the anti-249C antibody in serum of colon cancer patients appeared to be a linear fragment of the protein ARD1A. To confirm that peptide $249 \mathrm{C}$ is an epitope of ARD1A, the anti-249C antibody was obtained by immunization of BALB/C mice with GST-249C fusion protein and used in Western blotting. As shown in Figure 1B lane 4, the antibody against peptide $249 \mathrm{C}$ specifically reacted with recombinant His-ARD1A protein from bacteria and endogenous ARD1A from colon cancer LoVo cells. Furthermore, the molecular mimicry between the selected peptide 249C and ARD1A was shown by reciprocal co-IP assays (Figure $1 \mathrm{C}$ ). These data clearly demonstrated that anti-249C and anti-ARD1A antibodies recognized the same antigen, ARD1A.

By sequence alignment, 23\% sequence homology was found between ARD1A and human Mak3 homolog in complex with acetyl-coenzyme A (PDB ID: 2OBO). Using $2 \mathrm{OBO}$ as the model, a three-dimensional structure of ARD1A was predicted. As shown in Figure 1D, the LYSNTL region was on the surface of ARD1A and might contribute to an important external epitope of ARD1A. 
A

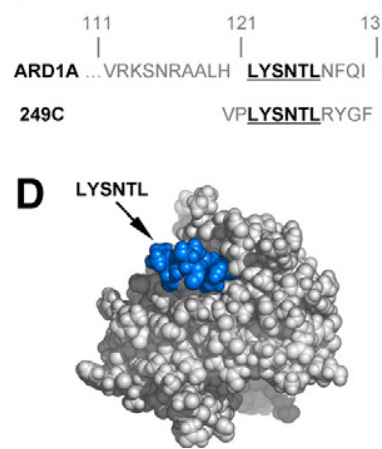

B

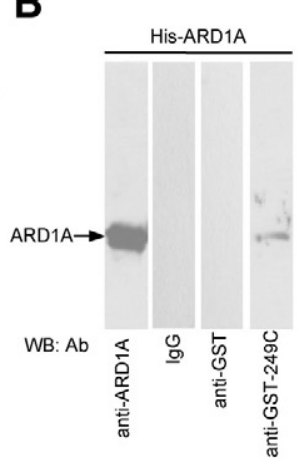

C

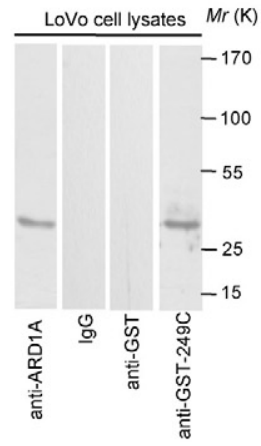

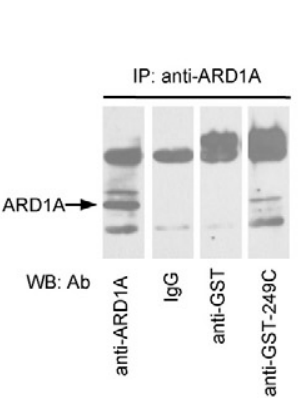

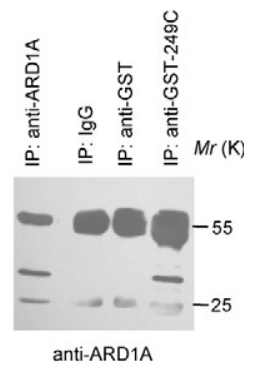

anti-ARD1A

Figure 1. Peptide 249C mimics the epitope of the ARD1A autoantigen. A: Amino acid sequences of ARD1A and peptide 249C. Bolded, underlined residues are the minimal motif shared by ARD1A and peptide 249C. B: Western blotting of anti-249C serum binding to ARD1A. Equal amounts of His-ARD1A (100 ng, left panel) or LoVo cell lysates (containing $100 \mu \mathrm{g}$ of total protein, right panel) were subjected to $12 \%$ SDS-PAGE and transferred to nitrocellulose membrane. Western blotting was performed with mouse anti-GST-249C serum at 1:50 dilution. Anti-ARD1A antibody 14D4 was used as a positive control. Preimmune mouse serum (IgG) and mouse anti-GST serum served as negative controls. C: Reciprocal coimmunoprecipitations with either anti-ARD1A or anti-GST-249C antibody show anti-249C antibody binding to ARD1A. Total cell lysate was isolated from LoVo cells, and equal amount of protein was subjected to IP with anti-ARD1A antibody (left panel), followed by Western blotting probed with mouse anti-GST-249C serum at 1:50. Anti-ARD1A antibody 14D4 was used as a positive control. Preimmune mouse serum (IgG) and mouse anti-GST serum served as negative controls. In the right panel, equal amount of total protein from LoVo cells was subjected to IP with mouse anti-GST-249C serum, anti-ARD1A antibody (positive control), preimmune mouse serum (IgG, negative control), or mouse anti-GST serum (negative control), followed by Western blotting performed with anti-ARD1A antibody 14D4. D: Epitope (peptide 249C) projected on the atomic structure of ARD1A using the Insight II (2000) software package. The sequence of the predicted ARD1A epitope LYSNTL is shown in blue. Amino acids used to fill in the predicted segments are shown in light gray.

Although peptides 164B, 283B, 93A, and 211B, which specifically reacted with serum from patients with colon cancer, were also obtained, we did not identify the corresponding target antigens for these peptide mimics (data not shown).

\section{The Level of Serum Antibody against ARD1A Being Significantly Different Between Colon Cancer Patients and Healthy Volunteers}

We speculated that the peptide 249 C was a distinct epitope on ARD1A. Thus, we determined the presence of antibodies to recombinant ARD1A in serum from 198 colon cancer patients and 200 healthy volunteers with ELISA. When the cutoff was set at OD $=0.415$, serum from patients with colon cancer was more likely to have detectable antibodies specific for ARD1A than samples from healthy volunteers, indicating that humoral immunity against ARD1A increased significantly $(P<0.001)$ from $2.0 \%(4 / 200)$ in healthy volunteers to $14.7 \%(29 / 198)$ in colon cancer patients (Figure 2A). Although we found no association between anti-ARD1A antibody immunity and clinicopathological variables (see Supplemental Table S2 at http://ajp.amjpathol.org), the observations suggested that humoral immunity to ARD1A readily distinguished patients with colon cancer from control subjects.

\section{ARD1A Being Highly Expressed in Colon Cancer Tissues}

Because the presence of circulating autoantibodies against ARD1A was associated with colon cancer, we further investigated the expression of ARD1A in matched cancerous, adjacent noncancerous, and distant noncancerous colon tissues from 40 patients by Western blotting. Compared with adjacent and distant noncancerous tissue, ARD1A expression was up-regulated in 28 (70.0\%) and down-regulated in $12(30.0 \%)$ of 40 patients in the cancer tissues by Western blotting (Figure 2B, see Supplemental Figure S1, and Supplemental Table S4 at http://ajp.amjpathol.org). These data suggested that ARD1A expression was higher in cancerous tissues than in noncancerous tissues. However, more colon samples are required to further confirm this results.

\section{ARD1A Overexpression in Colon Cancer Is Associated with Poor Prognosis for DFS and $O S$}

Next, we sought to examine the expression level of ARD1A in large cohort of tissue sample by immunohistochemical analysis. The frequency of ARD1A expression is shown in Supplemental Table S5 at http://ajp.amjpathol. org. When the frequency of expression was stratified into two groups-negative (0) and positive $(1+, 2+$, and $3+)-84.1 \%(227 / 270)$ of cancer tissues stained for ARD1A in $\geq 10 \%$ of tumor cells. As shown in Figure $2 \mathrm{C}$, ARD1A staining exhibited strong peri-nuclear pattern. In contrast, ARD1A expression was detected in 22.7\% (55/ 242) of matched adjacent noncancerous tissues. Only $4.8 \%$ (2/42) of benign lesions showed ARD1A expression, indicating that ARD1A expression was significantly more frequent in colon cancer tissues than in matched adjacent noncancerous tissues $(P<0.001)$ and benign lesions $(P<0.001)$ (see Supplemental Table S5 at http://ajp.amjpathol.org).

We further investigated the clinical relevance of differential ARD1A expression in tumor tissues. Clinicopathological variables of ARD1A-positive and ARD1A-negative patients were summarized in Supplemental Table S3 at http://ajp.amjpathol.org. ARD1A expression in tumor tissues exhibited no correlation with age, sex, tumor size, 


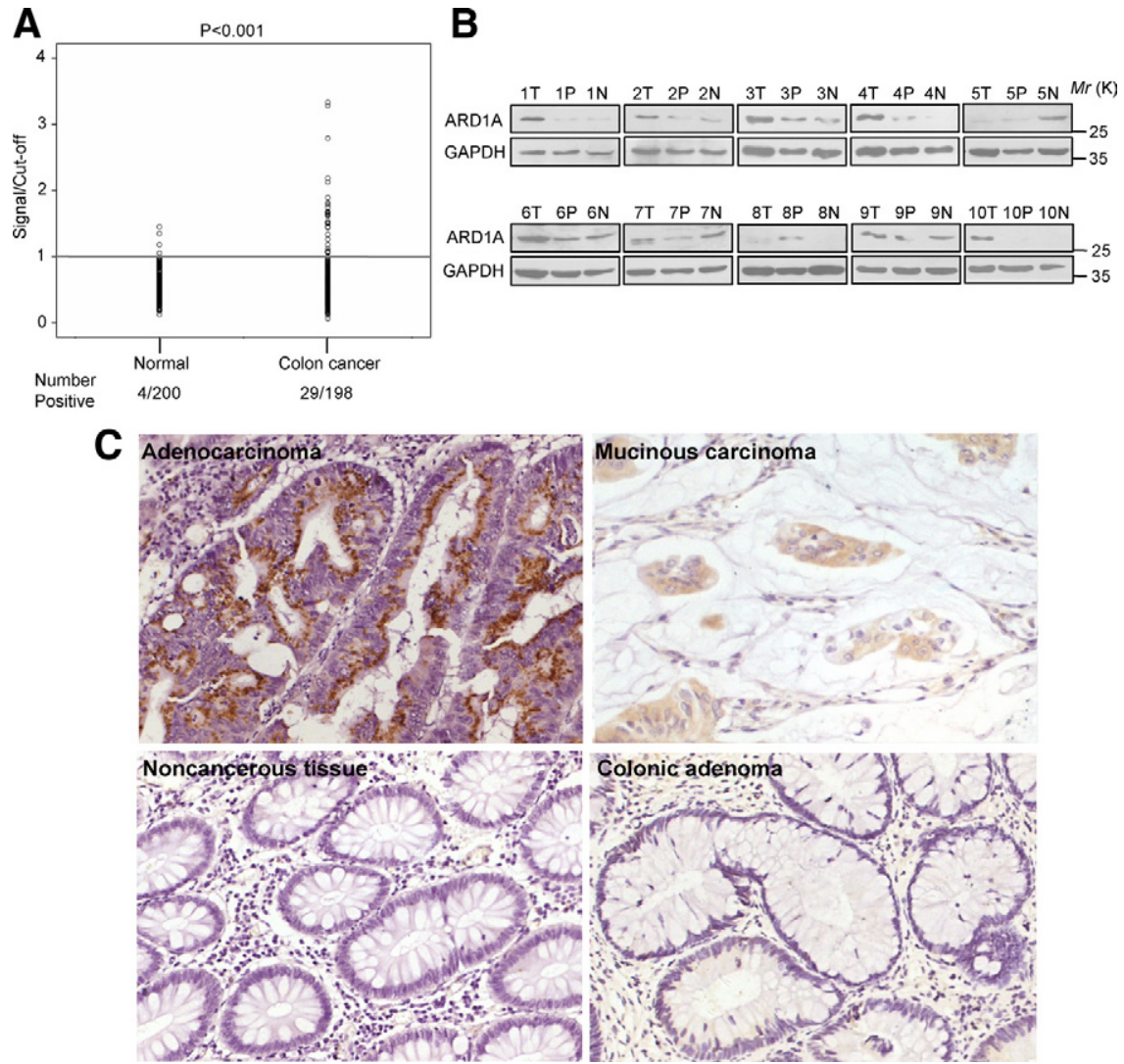

Figure 2. Clinical analysis of ARD1A characteristics. A: Antibody responses to ARD1A in serum from colon cancer patients and healthy volunteers. There is a significant difference in the seroreactivity to ARD1A between patients with colon cancer ( $n=198)$ and healthy volunteers $(n=200)$. His-ARD1A was coated onto a microtiter plate, and its reactivity to a panel of serum samples was evaluated using ELISA. The scattergram shows the ratio of the sample ELISA absorbance value to the cutoff. A ratio of $>1$ indicates a positive reaction. Data are representative of two experiments with similar results. B: Western blotting analysis of ARD1A expression in colon cancer tissues. Tissue proteins of $40 \mu \mathrm{g}$ were subjected to $12 \%$ SDS-PAGE and transferred to nitrocellulose membranes. Blots were probed with anti-ARD1A antibody (upper panel) or anti-GAPDH (lower panel). The results of ten representative patients are shown. $T$ indicates colon cancer tissue; $\mathrm{P}$, noncancerous tissue adjacent to tumor; $\mathrm{N}$, distant noncancerous tissue from the surgical margin. Detection of GAPDH was used as loading control. C: Immunohistochemical analysis of ARD1A expression in colon tissues. Brown staining in cytoplasm of colorectal cells indicates ARD1A expression. Sections were counterstained with hematoxylin. Colon cancer tissues stained strongly in adenocarcinoma and mucinous carcinoma. Negative staining of ARD1A in noncancerous tissue adjacent to tumor, and colonic adenoma is shown. Magnification, $\times 200$.

degree of lymph node status, clinical stage, or relapse status. We found a significant correlation only with tumor histological type and patient survival $(P<0.001$ and $P=$ 0.030 , respectively).

To determine whether ARD1A is a prognostic factor for colon cancer, Kaplan-Meier survival curves and the Cox proportional hazard model were used to evaluate the association between ARD1A-positive tumors and survival outcome in 270 colon cancer patients. Kaplan-Meier survival curves showed that patients with ARD1A-positive tumors had substantially shorter DFS and OS $(P=0.037$ and $P=0.019$, respectively) than patients with ARD1Anegative tumors (Figure $3 A$ ). The 5-year survival rate of patients whose tumors had higher ARD1A expression was $53.0 \%$, and this strongly contrasted with those having lower ARD1A expression (70.9\%; $P=0.019$ ).

In multivariate Cox regression analyses, ARD1A-positive status was found to be significantly associated with a shorter OS (HR, 1.91; 95\% Cl, 1.03-3.52; $P=0.039)$ and retained a borderline significance for shorter DFS (HR, 1.70; 95\% $\mathrm{Cl}, 0.96-3.00 ; P=0.068$ ) in patients with colon cancer. The results suggest that there is approximately a $91 \%$ and $70 \%$ increase in the risk of death and relapse, respectively, in patients with $A R D 1 A$-positive tumors compared with ARD1A negative tumors (Table 2). Therefore, ARD1A expression was a potential variable for prediction of OS and DFS in patients with colon cancer. As expected, clinical stage was an independent predictor for poor OS and DFS in multivariate analyses. Patient age, sex, and histological type were not significant predictors of OS and DFS in multivariate analyses (Table 2).
To evaluate the prognostic effect of ARD1A expression in each tumor stage, we did a stratified analysis by TNM staging. As shown in the Kaplan-Meier survival curves, ARD1A was significantly associated with shorter OS in stage II colon cancer patients $(P=0.044)$. However, ARD1A was not associated with prognosis in stage I, stage III, or stage IV patients (see Supplemental Figures S2 and Figure S3 at http://ajp.amjpathol.org). The multivariate analysis with the series stratified according to stage confirmed that the prognostic influence of ARD1A expression is different in tumor stages (see Supplemental Table S6 at http://ajp.amjpathol.org).

For further analysis, patient data were divided into two subgroups according to nodal status (node-negative or node-positive). In node-positive patients, ARD1A expression was significantly associated with OS based on the log-rank test. Patients with high ARD1A expression had a 5 -year overall survival rate of $31.6 \%$, compared with $56.5 \%$ among patients with low ARD1A expression ( $P=$ 0.039 , Figure 3B). Among the 123 patients with nodepositive disease, 74 of 106 (69.8\%) patients with high ARD1A expression died of cancer-related causes, but only 7 of $17(41.1 \%)$ patients with low ARD1A expression died during follow-up. In multivariate Cox regression analysis, ARD1A showed a statistical significance for worse OS (HR, 2.76; 95\% Cl, 1.15-6.61; $P=0.023)$ and DFS (HR, 2.43; 95\% Cl, 1.08-5.43; $P=0.031)$ in nodepositive patients after adjusting for age, sex, and histological type (Table 3). In contrast, there was no significant correlation between the ARD1A expression and OS or DFS in patients with node-negative disease $(P=0.352$ 
A
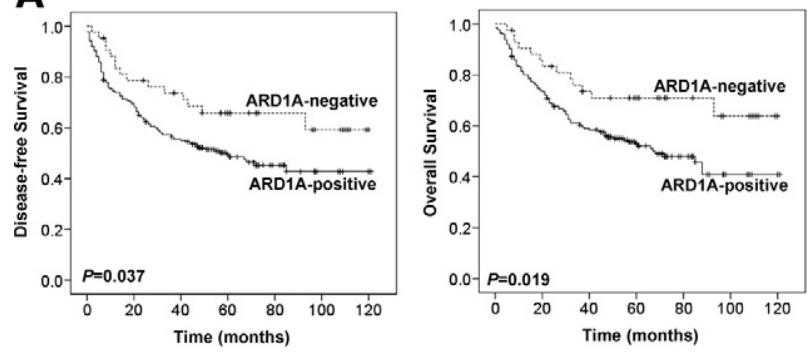

B
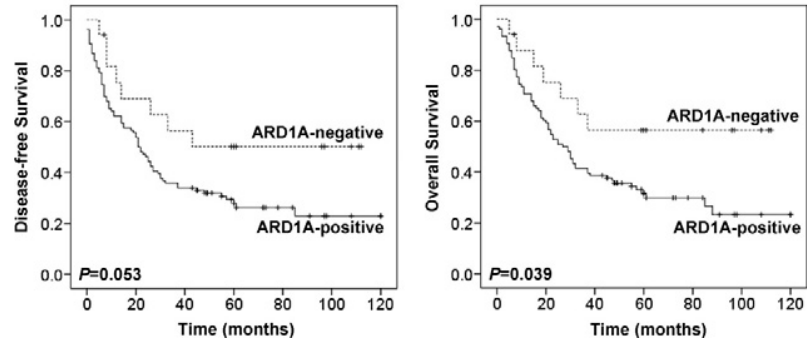

Figure 3. DFS and OS of patients with colon cancer according to Kaplan-Meier analysis. A: Kaplan-Meier survival curves for DFS (left panel) and OS (right panel) indicate that ARD1A-positive tumors are associated with a worse prognosis than ARD1A-negative tumors for patients with colon cancer. B: KaplanMeier survival curves for DFS (left panel) and OS (right panel) in node-positive patients indicate that ARD1A-positive tumors are associated with a worse prognosis than ARD1A-negative tumors for the node-positive patients.

and $P=0.479$, respectively; see Supplemental Figure S4 at http://ajp.amjpathol.org). Taken together, our data strongly suggest that ARD1A may act as an unfavorable prognostic factor for patients with colon cancer, especially those with node-positive tumors.

\section{Discussion}

In the present study, we screened and validated a peptide mimic in a large panel of serum samples derived from patients with colon cancer. Although there are many candidate proteins containing six continuous amino acids of peptide $249 \mathrm{C}$ by BLAST homology search, anti-
249C polyclonal antibody could only detect a single highly immunoreactive band at around $30 \mathrm{kDa}$ in the $15 \mathrm{kDa}$ to $170 \mathrm{kDa}$ mass range by Western blotting of LoVo cell lysates (Figure 1B). The band corresponded well to the expected size of ARD1A, a protein with a predicted molecular weight of $26.5 \mathrm{kDa}$. Thus, we speculated that ARD1A might be the corresponding autoantigen of the peptide 249C. Further analysis by IP, Western blotting, and three-dimensional structure prediction verified that 249C shared an epitope of ARD1A.

Besides measuring serum antigens, the detection of serum antibody responses to tumor antigens might provide a more reliable serum marker for cancer diagnosis, because serum antibodies might be more abundant and stable than serum antigens, especially in patients with a low tumor burden. ${ }^{5-7}$ Changes in the level of gene expression and aberrant expression of gene products in tumor are elements in the development of humoral immune responses in patients with cancer..$^{8,17-19}$ In this study, although ARD1A protein was not detectable in serum from colon cancer patients under our experimental conditions (data not shown), the immune response against ARD1A could distinguish patients with colon cancer from healthy volunteers.

ARD1A interacts with human $\mathrm{N}$-acetyltransferase (NATH) to form the functional NAT. ${ }^{20}$ Although the substrates of ARD1A and NATH remain largely unknown, several recent studies have shown that ARD1A is important for cell viability and proliferation. ${ }^{21-23}$ When ARD1A and NATH were knocked down by siRNAs, a reduction in cell viability and proliferation as well as an increase in daunorubicin-induced apoptosis was observed. ${ }^{21}$ Moreover, down-regulation of ARD1A led to the inactivation of $\beta$-catenin, which in turn reduced cyclin D1 transcription and induced cell growth arrest in the G1/G0 phase..22 However, another report showed that siRNAs against ARD1A provided strong cell protection against DNA damage-induced apoptosis. ${ }^{24}$ Thus, the role of ARD1A in apoptosis regulation deserves further investigation.

We speculated that the development of a humoral immune response against ARD1A occurs as a direct

Table 2. Multivariate Analysis of ARD1A in Patients with Colon Cancer with Respect to DFS and OS

\begin{tabular}{|c|c|c|c|c|c|c|}
\hline \multirow[b]{2}{*}{ Variable } & \multicolumn{3}{|c|}{ DFS } & \multicolumn{3}{|c|}{ OS } \\
\hline & $\mathrm{HR}$ & $95 \% \mathrm{Cl}$ & $P$ & $\mathrm{HR}$ & $95 \% \mathrm{Cl}$ & $P$ \\
\hline \multicolumn{7}{|l|}{ Age, years } \\
\hline$\geq 50$ & 1.00 & & & 1.00 & & \\
\hline$<50$ & 0.84 & $0.54-1.29$ & 0.414 & 0.76 & $0.49-1.18$ & 0.217 \\
\hline \multicolumn{7}{|l|}{ Sex } \\
\hline Male & 1.00 & & & 1.00 & & \\
\hline Female & 1.07 & $0.75-1.52$ & 0.714 & 1.10 & $0.77-1.58$ & 0.598 \\
\hline \multicolumn{7}{|l|}{ TNM stage } \\
\hline I & 1.00 & & & 1.00 & & \\
\hline$\|$ & 1.60 & $0.69-3.69$ & 0.271 & 1.80 & $0.74-4.42$ & 0.197 \\
\hline III & 3.95 & $1.78-8.75$ & 0.001 & 4.16 & $1.77-9.78$ & 0.001 \\
\hline IV & 13.50 & $6.00-30.39$ & 0.000 & 18.42 & $7.71-43.97$ & 0.000 \\
\hline \multicolumn{7}{|l|}{ Histological type } \\
\hline Mucinous carcinoma & 1.00 & & & 1.00 & & \\
\hline Adenocarcinoma & 1.17 & $0.85-1.60$ & 0.346 & 1.19 & $0.85-1.65$ & 0.313 \\
\hline \multicolumn{7}{|l|}{ ARD1A } \\
\hline Negative & 1.00 & & & 1.00 & & \\
\hline Positive & 1.70 & $0.96-3.00$ & 0.068 & 1.91 & $1.03-3.52$ & 0.039 \\
\hline
\end{tabular}


Table 3. Multivariate Analysis of ARD1A in Node-Positive Patients Respect to DFS and OS

\begin{tabular}{|c|c|c|c|c|c|c|}
\hline \multirow[b]{2}{*}{ Variable } & \multicolumn{3}{|c|}{ DFS } & \multicolumn{3}{|c|}{ OS } \\
\hline & $\mathrm{HR}$ & $95 \% \mathrm{Cl}$ & $P$ & $\mathrm{HR}$ & $95 \% \mathrm{Cl}$ & $P$ \\
\hline \multicolumn{7}{|l|}{ Age, years } \\
\hline$\geq 50$ & 1.00 & & & 1.00 & & \\
\hline$<50$ & 0.95 & $0.56-1.62$ & 0.858 & 0.93 & $0.55-1.59$ & 0.779 \\
\hline \multicolumn{7}{|l|}{ Sex } \\
\hline Male & 1.00 & & & 1.00 & & \\
\hline Female & 0.85 & $0.56-1.31$ & 0.467 & 0.92 & $0.59-1.43$ & 0.703 \\
\hline \multicolumn{7}{|l|}{ Histological type } \\
\hline Mucinous carcinoma & 1.00 & & & 1.00 & & \\
\hline Adenocarcinoma & 1.30 & $0.83-2.04$ & 0.246 & 1.33 & $0.82-2.14$ & 0.248 \\
\hline \multicolumn{7}{|l|}{ ARD1A } \\
\hline Negative & 1.00 & & & 1.00 & & \\
\hline Positive & 2.43 & $1.08-5.43$ & 0.031 & 2.76 & $1.15-6.61$ & 0.023 \\
\hline
\end{tabular}

result of changes in the level of ARD1A expression or aberrant expression of ARD1A gene products in colon cancer. Thus, we sought to determine the expression status of ARD1A in colon cancer. Previous studies showed that ARD1A is ubiquitously expressed in various human tissues, including brain, heart, skeletal muscle, and liver, at the mRNA level. ${ }^{25}$ Bilton et al reported that ARD1A is a stable protein expressed in a broad range of tissues, tumor cell lines, and endothelial cells. ${ }^{26}$ However, there is limited information on ARD1A expression in cancer tissues. For example, in hepatocellular carcinoma, ARD1A is found to be significantly elevated in moderately differentiated tumors compared with in welldifferentiated tumors. ${ }^{27}$ Using immunohistochemical analysis, Yu et al found that ARD1A protein is expressed extensively in cancer tissues, including glandular carcinoma and squamous cancer. ${ }^{28}$ In contrast, Arnesen et al reported that ARD1A is down-regulated in 16 of 27 thyroid neoplasms compared with nonneoplastic tissues. ${ }^{29}$ Collectively, the difference in ARD1A expression suggests that the role of ARD1A in different cancers may vary considerably, depending on the tissue involved. In our previous study, ARD1A expression was detected in 41 of $50(82 \%)$ colorectal cancer tissues. ${ }^{15}$ In the present study, ARD1A expression was determined in 270 colon cancer tissues and 242 matched adjacent noncancerous tissues. Our results are consistent with the report by Yu et al that colon cancer tissues are more often ARD1A-positive than are corresponding noncancerous tissues. ${ }^{28} \mathrm{Al}-$ though tumor ARD1A expression had no correlation with almost all of the clinicopathological variables, patients with ARD1A-positive colon tumors had a shorter DFS and OS than those with ARD1A-negative tumors. These findings further validate the association between ARD1A expression and poor prognosis, given that patients with ARD1A-positive tumors have a relatively worse clinical outcome as evidenced by multivariate Cox proportional hazards regression analysis and Kaplan-Meier survival curves. Thus, ARD1A expression may serve as an unfavorable prognostic factor in patients with colon cancer particularly for node-positive patients.

In our study, the frequency of antibody responses to ARD1A in serum from colon cancer patients was lower than ARD1A expression in colon cancer tissues. Similar antibody responses have been reported for other cancer biomarkers, such as HER-2. Although the presence of antibodies to HER-2 correlates with HER-2 overexpression in cancer patients, only $20 \%$ of patients with HER2-positive tumors have HER-2-specific antibodies, ${ }^{6,7}$ perhaps due to impaired immune response in cancer patients. As the 198 of serum samples and 270 tumor samples used in this study were from the different population, to evaluate the association between ARD1A expression and antibodies to ARD1A in serum, an analysis of 40 additional cancer patients with serum samples and tumor specimens was performed. We didn't find any correlation between ARD1A expression and ARD1A antibody level $(P=0.622$, see Supplemental Table $S 4$ at http://ajp.amjpathol.org). However, there were only 30 serum samples involved in the study, and more samples are required for confirming these results.

In summary, by screening a phage display peptide library, we found that peptide 249C containing the ARD1A motif LYSNTL specifically reacted with serum antibodies from patients with colon cancer, and the antibody against $249 \mathrm{C}$ could recognize ARD1A as well. These data, in addition to the three-dimensional structure prediction, indicated that the motif LYSNTL was the epitope of ARD1A, and ARD1A could be a tumor-associated antigen. Furthermore, we found that the level of serum antibodies to ARD1A was significantly higher in colon cancer patients than in the healthy volunteers, and ARD1A expression was higher in colon cancer tissues than in matched noncancerous tissues. Patients with ARD1A-positive tumors had a statistical and borderline statistical shorter OS and DFS, respectively. Thus, ARD1A overexpression is associated with poor prognosis in colon cancer. This is the first clinical study to correlate ARD1A expression with clinical outcome for colon cancer patients. Future studies are needed to confirm this association as well as to elucidate the mechanisms by which ARD1A affects the progression of colon cancer.

\section{Acknowledgments}

We thank the Tissue Bank of Peking University School of Oncology for providing the specimens. We thank Dr. Jiyou Li for histopathological diagnosis. 


\section{References}

1. Levin B, Lieberman DA, McFarland B, Andrews KS, Brooks D, Bond J, Dash C, Giardiello FM, Glick S, Johnson D, Johnson CD, Levin TR, Pickhardt PJ, Rex DK, Smith RA, Thorson A, Winawer SJ: Screening and surveillance for the early detection of colorectal cancer and adenomatous polyps, 2008: a joint guideline from the American Cancer Society, the US Multi-Society Task Force on Colorectal Cancer, and the American College of Radiology. Gastroenterology 2008, 134:1570-1595

2. Wolpin BM, Mayer RJ: Systemic treatment of colorectal cancer. Gastroenterology 2008, 134:1296-1310

3. Wang X, Yu J, Sreekumar A, Varambally S, Shen R, Giacherio D, Mehra R, Montie JE, Pienta KJ, Sanda MG, Kantoff PW, Rubin MA, Wei JT, Ghosh D, Chinnaiyan AM: Autoantibody signatures in prostate cancer. N Engl J Med 2005, 353:1224-1235

4. Mintz PJ, Kim J, Do KA, Wang X, Zinner RG, Cristofanilli M, Arap MA, Hong WK, Troncoso P, Logothetis CJ, Pasqualini R, Arap W: Fingerprinting the circulating repertoire of antibodies from cancer patients. Nature Biotechnol 2003, 21:57-63

5. Soussi T: p53 Antibodies in the sera of patients with various types of cancer: a review. Cancer Res 2000, 60:1777-1788

6. Disis ML, Calenoff E, McLaughlin G, Murphy AE, Chen W, Groner B, Jeschke M, Lydon N, McGlynn E, Livingston RB, Moe R, Cheever MA: Existent T-cell and antibody immunity to HER-2/neu protein in patients with breast cancer. Cancer Res 1994, 54:16-20

7. Disis ML, Pupa SM, Gralow JR, Dittadi R, Menard S, Cheever MA: High-titer HER-2/neu protein-specific antibody can be detected in patients with early-stage breast cancer. J Clin Oncol 1997, 15:33633367

8. Chen YT, Scanlan MJ, Sahin U, Türeci O, Gure AO, Tsang S, Williamson B, Stockert E, Pfreundschuh M, Old LJ: A testicular antigen aberrantly expressed in human cancers detected by autologous antibody screening. Proc Natl Acad Sci USA 1997, 94:1914-1918

9. Naora H, Montz FJ, Chai CY, Roden RB: Aberrant expression of homeobox gene HOXA7 is associated with müllerian-like differentiation of epithelial ovarian tumors and the generation of a specific autologous antibody response. Proc Natl Acad Sci USA 2001, 98:15209-15214

10. Boon $T$, van der Bruggen $P$ : Human tumor antigens recognized by $T$ lymphocytes. J Exp Med 1996, 183:725-729

11. Stone B, Schummer M, Paley PJ, Thompson L, Stewart J, Ford M, Crawford M, Urban N, O'Briant K, Nelson BH: Serologic analysis of ovarian tumor antigens reveals a bias toward antigens encoded on 17q. Int J Cancer 2003, 104:73-84

12. Cekaite L, Haug O, Myklebost O, Aldrin M, Østenstad B, Holden M, Frigessi A, Hovig E, Sioud M: Analysis of the humoral immune response to immunoselected phage-displayed peptides by a microarray-based method. Proteomics 2004, 4:2572-2582

13. Luo W, Chen $Y$, Wang M, Chen $Y$, Zheng Z, Song $H$, Chen $H$, Guan $\mathrm{Y}, \mathrm{Ng} \mathrm{MH}$, Zhang J, Xia N: Peptide mimics of a conserved H5N1 avian influenza virus neutralization site. Biochem J 2009, 419:133-139

14. Jiang B, Liu W, Qu H, Meng L, Song S, Ouyang T, Shou C: A novel peptide isolated from a phage display peptide library with trastu- zumab can mimic antigen epitope of HER-2. J Biol Chem 2005, 280:4656-4662

15. Ren T, Jiang B, Jin G, Li J, Dong B, Zhang J, Meng L, Wu J, Shou C: Generation of novel monoclonal antibodies and their application for detecting ARD1 expression in colorectal cancer. Cancer Lett 2008 264:83-92

16. Xing X, Peng L, Qu L, Ren T, Dong B, Su X, Shou C: Prognostic value of PRL-3 overexpression in early stages of colonic cancer. Histopathology 2009, 54:309-318

17. Naora H, Yang YQ, Montz FJ, Seidman JD, Kurman RJ, Roden RB: A serologically identified tumor antigen encoded by a homeobox gene promotes growth of ovarian epithelial cells. Proc Natl Acad Sci USA 2001, 98:4060-4065

18. Brass N, Rácz A, Bauer C, Heckel D, Sybrecht G, Meese E: Role of amplified genes in the production of autoantibodies. Blood 1999, 93:2158-2166

19. Scanlan MJ, Gout I, Gordon CM, Williamson B, Stockert E, Gure AO, Jäger D, Chen YT, Mackay A, O'Hare MJ, Old LJ: Humoral immunity to human breast cancer: antigen definition and quantitative analysis of mRNA expression. Cancer Immun 2001, 1:4

20. Arnesen T, Anderson D, Baldersheim C, Lanotte M, Varhaug JE, Lillehaug JR: Identification and characterization of the human ARD1NATH protein acetyltransferase complex. Biochem J 2005, 386:433-443

21. Arnesen T, Gromyko D, Pendino F, Ryningen A, Varhaug JE, Lillehaug JR: Induction of apoptosis in human cells by RNAi-mediated knockdown of ARD1 and NATH, components of the protein Nalpha-acetyltransferase complex. Oncogene 2006, 25:4350-4360

22. Lim JH, Park JW, Chun YS: Human arrest defective 1 acetylates and activates beta-catenin, promoting lung cancer cell proliferation. Cancer Res 2006, 66:10677-10682

23. Fisher TS, Etages SD, Hayes L, Crimin K, Li B: Analysis of ARD1 function in hypoxia response using retroviral RNA interference. J Biol Chem 2005, 280:17749-11757

24. Yi CH, Sogah DK, Boyce M, Degterev A, Christofferson DE, Yuan J: A genome-wide RNAi screen reveals multiple regulators of caspase activation. J Cell Biol 2007, 179:619-626

25. Jeong JW, Bae MK, Ahn MY, Kim SH, Sohn TK, Bae MH, Yoo MA, Song EJ, Lee KJ, Kim KW: Regulation and destabilization of HIF1alpha by ARD1-mediated acetylation. Cell 2002, 111:709-720

26. Bilton R, Mazure N, Trottier E, Hattab M, Déry MA, Richard DE, Pouysségur J, Brahimi-Horn MC: Arrest-defective-1 protein, an acetyltransferase, does not alter stability of hypoxia-inducible factor (HIF)-1alpha and is not induced by hypoxia or HIF. J Biol Chem 2005 , 280:31132-31140

27. Midorikawa Y, Tsutsumi S, Taniguchi H, Ishii M, Kobune $Y$, Kodama T, Makuuchi M, Aburatani $\mathrm{H}$ : Identification of genes associated with dedifferentiation of hepatocellular carcinoma with expression profiling analysis. Jpn J Cancer Res 2002, 93:636-643

28. Yu M, Gong J, Ma M, Yang H, Lai J, Wu H, Li L, Li L, Tan D: Immunohistochemical analysis of human arrest-defective-1 expressed in cancers in vivo. Oncol Rep 2009, 21:909-915

29. Arnesen T, Gromyko D, Horvli O, Fluge $\varnothing$, Lillehaug J, Varhaug JE: Expression of $\mathrm{N}$-acetyl transferase human and human Arrest defective 1 proteins in thyroid neoplasms. Thyroid 2005, 15:1131-1136 